\title{
Effects of the planetary waves on the MLT airglow
}

\author{
Fabio Egito ${ }^{1}$, Hisao Takahashi ${ }^{2}$, and Yasunobu Miyoshi ${ }^{3}$ \\ ${ }^{1}$ Centro Multidisciplinar de Bom Jesus da Lapa, Universidade Federal do Oeste da Bahia, \\ Bom Jesus da Lapa, 47600-000, Brazil \\ ${ }^{2}$ Aeronomy Division, National Institute for Space Research, São José dos Campos, 12227-010, Brazil \\ ${ }^{3}$ Department of Earth and Planetary Sciences, Kyushu University, 744 Motooka Nishi-ku Fukuoka, 819-0395, Japan
}

Correspondence to: Fabio Egito (fabioegito@yahoo.com.br)

Received: 28 March 2017 - Revised: 18 July 2017 - Accepted: 18 July 2017 - Published: 31 August 2017

\begin{abstract}
The planetary-wave-induced airglow variability in the mesosphere and lower thermosphere (MLT) is investigated using simulations with the general circulation model (GCM) of Kyushu University. The model capabilities enable us to simulate the MLT OI557.7 nm, $\mathrm{O}_{2} b(0-1)$, and $\mathrm{OH}(6-2)$ emissions. The simulations were performed for the lowerboundary meteorological conditions of 2005. The spectral analysis reveals that at middle latitudes, oscillations of the emission rates with the period of 2-20 days appear throughout the year. The 2-day oscillations are prominent in the summer and the 5-, 10-, and 16-day oscillations dominate from the autumn to spring equinoxes. The maximal amplitude of the variations induced by the planetary waves was $34 \%$ in OI557.7 nm, $17 \%$ in $\mathrm{O}_{2} b(0-1)$, and $8 \%$ in $\mathrm{OH}(6-2)$. The results were compared to those observed in the middle latitudes. The GCM simulations also enabled us to investigate vertical transport processes and their effects on the emission layers. The vertical transport of atomic oxygen exhibits similar periodic variations to those observed in the emission layers induced by the planetary waves. The results also show that the vertical advection of atomic oxygen due to the wave motion is an important factor in the signatures of the planetary waves in the emission rates.
\end{abstract}

Keywords. Atmospheric composition and structure (airglow and aurora; middle atmosphere - composition and chemistry) - meteorology and atmospheric dynamics (waves and tides)

\section{Introduction}

Temporal variations in the airglow emission rates, which originated from the mesosphere and lower thermosphere
(MLT), are important features to understand the photochemical and dynamical processes in this region, and they have been extensively studied. Although the airglow is produced mainly thorough chemical reactions that involve minor constituents, dynamic processes that change the concentrations of the constituents are important factors in the time variation in the airglow. The airglow temporal variability ranges from short- (a few minutes) to long- (tens of days) term variations because of the solar and anthropogenic effects. In this context, dynamical processes induced by atmospheric waves, such as gravity waves, tides, and planetary waves, play an important role in causing the airglow variability. Historically, the Krassovsky parameter (Krassovsky, 1972) has been used to indicate the gravity-wave-induced perturbations in the airglow. Ground-based observations showed diurnal and semidiurnal variations in the airglow, which were explained by atmospheric tides (Wiens and Weill, 1972; Fukuyama, 1976). Using satellite observations, Shepherd et al. (2006) further studied the effect of tidal oscillations on the airglow variabilities. Combined observational and modeling studies have also helped to understand the interaction and effect of these waves in the emissions (Walterscheid and Schubert, 1995; Yee et al., 1997; Snively et al., 2010; Liu et al., 2008).

The airglow variability on a scale of days has been interpreted as a consequence of the passage of planetary waves through the emission layers. Both ground-based and satellite measurements have reported signatures of planetary-waveinduced airglow variability. Teitelbaum et al. (1981) presented one of the first reports of planetary-wave signatures in the airglow. They identified the presence of 2-day variation in the atomic oxygen green line and the meteor wind that was simultaneously measured at two middle-latitude stations in the Northern Hemisphere. Further study on the 
planetary-wave activity in the airglow was extended to cover latitudes from the pole to the equator. In the arctic region, the 5-day, 10-day, and 16-day periodic variations in the emission rates have been attributed to the Rossby normal modes (Sivjee et al., 1994; Espy et al., 1996, 1997). In the middle latitudes, Lopez-Gonzalez et al. (2009) presented an extensive statistical study about the occurrence and characteristics of planetary-wave signatures in the hydroxyl and molecular oxygen airglow intensities and the respective rotational temperatures. In the equatorial region, Takahashi et al. (2002) and Buriti et al. (2005) reported 3-4-day periodic oscillations in the airglow intensities, which were attributed to the 3.5day ultra-fast Kelvin wave. Measurements by the WINDII instrument (Wind Imager Interferometer) on board the UARS satellite (Upper Atmosphere Research Satellite) enabled the observation of planetary-scale structures in the airglow emission rates (Shepherd et al., 1993). From this dataset, Ward et al. (1997) retrieved the signature of 2-day waves in the atomic oxygen green line. Other satellite-borne studies (e.g., Liu and Shepherd, 2006; Xu et al., 2010) have reported longitudinal variations in the MLT airglow and associated them with the passage of planetary-scale waves through the emission layers.

Many previous studies on the airglow variability have focused on observing the planetary-wave activity, but modeling studies have not been fully explored. Walterscheid and Schubert (1995) investigated the effects of the planetary-wave normal modes on the $\mathrm{OH}$ emission using the Krassosvky theory for an isothermal, inviscid, and windless atmosphere. Lichstein et al. (2002) used a one-dimensional model to simulate the 3.5-day oscillation of the airglow intensities that Takahashi et al. (2002) observed. They concluded that the observed oscillation was consistent with an ultra-fast Kelvin wave.

Observational evidence and numerical simulations have indicated that vertical transport is mainly responsible for the observed airglow variations (Shepherd et al., 2006; Liu et al., 2008). Cho and Shepherd (2006) argued that the underlying process behind both short- and long-term airglow variations most likely involve vertical motions, which act on the atomic oxygen transport. Combining atomic oxygen OI557.7 nm emission measurements by WINDII with TIME-GCM (Thermosphere-Ionosphere-Mesosphere Electrodynamics general circulation model) simulations, Liu et al. (2008) showed that the daily airglow variability is a straightforward result of the vertical transport of atomic oxygen due to the tidal vertical motions. Concerning planetary waves, Ward et al. (1997) pointed out that the vertical transport of atomic oxygen is responsible for the observed 2day variations in the atomic oxygen green line measured by WINDII. Nevertheless, it is unclear whether their proposed mechanism holds for longer-period waves such as 5-, 10-, and 16-day planetary waves.

Although the activity and some characteristics of the induced airglow variations by planetary-scale waves are rela- tively well known, their effects on the composition of constituents such as atomic oxygen and the consequent airglow variations are not well understood. In the present study, we used the Kyushu general circulation model to simulate airglow emissions coming from the MLT region to investigate the activity of the planetary waves. Then, we used the simulations to investigate the mechanisms responsible for the planetary-wave-induced variations in the airglow emissions.

\section{Data and simulation model}

In this study, we numerically simulated the temporal variation in the airglow emission rates by using the general circulation model of Kyushu University (hereafter abbreviated as Kyushu GCM). The Kyushu GCM is a global spectral model, which was originally developed as a meteorological and climate model and extended to the middle and upper atmosphere at Kyushu University (Miyahara et al., 1993). The model contains a vertical extension from the ground to the exobase (approximately $500 \mathrm{~km}$ ), where the set of non-linear equations for the zonal and meridional momentum budget, thermodynamics, continuity, and hydrostatic is solved at constant pressure levels. The model incorporates a full set of appropriate physical processes for the troposphere, stratosphere mesosphere, and thermosphere. The effects of the Earth surface topography, contrast between land and sea temperatures, and moist convection are considered. The model also includes the assimilation of the meteorological reanalysis data from the JRA-25 project (25-year Japanese ReAnalysis) (Onogi et al., 2005). Using a nudging technique, the solutions of the equations are forced towards reanalysis data from the ground to approximately $30 \mathrm{~km}$ in altitude. The Kyushu GCM has a spectral model of T42, which corresponds to a $2.8^{\circ}$ horizontal resolution in longitude and latitude. It contains 75 vertical layers with a vertical resolution of 0.4-scale height above the troposphere, which corresponds to approximately $2 \mathrm{~km}$ in the MLT heights. Further details can be found elsewhere (Miyoshi et al., 1999, 2003, 2006).

\subsection{Airglow photochemistry}

The interaction between airglow layers and atmospheric waves has been modeled using different approaches. For gravity waves, there are one-dimensional models that consider basic photochemistry and dynamics and threedimensional models with basic steady-state photochemistry and realistic nonlinear wave dynamics (e.g., Vargas et al., 2007; Snively et al., 2010; Horinouchi, 2004). Various studies have used one-dimensional numerical models to investigate the effects of large-scale waves such as tides and planetary and Kelvin waves on the airglow (e.g., Walterscheid and Schubert, 1995; Angelatis i Coll and Forbes, 1998; Lichstein et al., 2002). Recently, Liu et al. (2008) used the threedimensional TIME-GCM model to study the seasonal and 
tidal variations in the $\mathrm{O}\left({ }^{1} \mathrm{~S}\right)$ and $\mathrm{OH}$ emissions. The approach used to simulate the airglow intensity variability in different dynamical processes depends on the characteristics of the model and the purpose of the study. To simulate airglow emissions by using the Kyushu GCM, we used the steadystate photochemistry approach. In this case, we have considered the photochemical balance between the production and loss processes to simulate the emissions rates. Dynamical effects of the waves were incorporated into the constituents and temperature, which was originally calculated in the model. In this study, we simulated the OI557.7 nm (hereafter OI5577), $\mathrm{O}_{2} b(0-1)$ band (hereafter $\left.\mathrm{O}_{2} b(0-1)\right)$, and $\mathrm{OH}(6-2)$ band (hereafter $\mathrm{OH}(6-2)$ ) MLT airglow emissions, which enabled further comparison with ground-based observations. In the next section, we describe the basic photochemistry of each emission.

\subsubsection{The OI5577 and $\mathrm{O}_{2} b(0-1)$ emissions}

It is well established that the excited state responsible for the OI5577 green line emission in the MLT is produced by the two-step Barth's mechanism (Barth, 1961). In this mechanism a three-body recombination reaction between two oxygen atoms in the presence of a third body produces an excited state of the molecular oxygen, which subsequently reacts with other atomic oxygen and produces the excited state:

$\mathrm{O}+\mathrm{O}+M \rightarrow \mathrm{O}_{2}{ }^{*}+M$,

$\mathrm{O}_{2}{ }^{*}+\mathrm{O} \rightarrow \mathrm{O}\left({ }^{1} \mathrm{~S}\right)+\mathrm{O}_{2}$,

where $M=\mathrm{O}_{2}+\mathrm{N}_{2}$ is the atmospheric third body and $\mathrm{O}_{2}{ }^{*}$ is an intermediate excited state.

The production mechanism of the excited state of the $\mathrm{O}_{2} b(0-1)$ atmospheric band is similar to that of the OI5577 green line, but in the second step, the energy is transferred from the $\mathrm{O}_{2}^{*}$ excited state to the molecular oxygen instead of the atomic oxygen. The reactions are as follows:

$\mathrm{O}+\mathrm{O}+M \rightarrow \mathrm{O}_{2}{ }^{*}+M$,

$\mathrm{O}_{2}{ }^{*}+\mathrm{O}_{2} \rightarrow \mathrm{O}_{2}\left(b^{1} \Sigma_{\mathrm{g}}^{+}\right)+\mathrm{O}_{2}$.

Loss processes for $\mathrm{O}\left({ }^{1} \mathrm{~S}\right)$ and $\mathrm{O}_{2}\left(b^{1} \Sigma_{\mathrm{g}}^{+}\right)$occur via quenching and radiative decay and must be considered for the $\mathrm{O}_{2}^{*}$.

Considering the photochemical balance equations presented by McDade et al. (1986), the volumetric emission rates of the $\mathrm{OI} 5577$ and $\mathrm{O}_{2} b(0-1)$ can be calculated as

$$
\begin{aligned}
& V_{\mathrm{O} I 5577}=\frac{A_{5} k_{1}[\mathrm{O}]^{3}\left(\left[\mathrm{~N}_{2}\right]+\left[\mathrm{O}_{2}\right]\right)}{\left(A_{6+} k_{5}\left[\mathrm{O}_{2}\right]\right)\left(\mathrm{C}_{\mathrm{O}_{2}}{ }^{\prime}\left[\mathrm{O}_{2}\right]+\mathrm{C}_{\mathrm{O}}[\mathrm{O}]\right)}, \\
& V_{\mathrm{O}_{2(0-1)}}=\frac{A_{1} k_{1}\left[\mathrm{O}_{2}\right][\mathrm{O}]^{2}\left(\left[\mathrm{~N}_{2}\right]+\left[\mathrm{O}_{2}\right]\right)}{\left(A_{2+} k_{2}^{\mathrm{O}_{2}}\left[\mathrm{O}_{2}\right]+k_{2}^{\mathrm{N}_{2}}\left[\mathrm{~N}_{2}\right]\right)\left(\mathrm{C}_{\mathrm{O}_{2}}\left[\mathrm{O}_{2}\right]+\mathrm{C}_{\mathrm{O}}[\mathrm{O}]\right)},
\end{aligned}
$$

where $A_{1}, A_{2}, A_{5}$, and $A_{6}$ are the transition probabilities, $k_{1}, k_{2}, k_{2}^{\mathrm{O}_{2}}$, and $k_{2}^{\mathrm{N}_{2}}$ are the reaction coefficients, and $\mathrm{C}_{\mathrm{O}_{2}}^{\prime}$, $\mathrm{C}_{\mathrm{O}}^{\prime}, \mathrm{C}_{\mathrm{O}_{2}}$, and $\mathrm{C}_{\mathrm{O}}$ are constants, which were obtained from McDade et al. (1986) and references therein.

\subsubsection{The $\mathrm{OH}$ emission}

The main source of the airglow $\mathrm{OH}$ Meinel bands is the exothermic reaction between ozone and hydrogen (Bates et al., 1950):

$\mathrm{H}+\mathrm{O}_{3} \rightarrow \mathrm{OH}^{*}(v \leq 9)+\mathrm{O}_{2}$,

where $v$ is the vibrational level of the $\mathrm{OH}$ molecule.

Lower vibrational levels are also populated by collisional and radiative cascade. The loss processes include quenching and radiative relaxation. In the nighttime MLT, the ozone is produced in the recombination reaction $\mathrm{O}_{2}+\mathrm{O}+M \rightarrow$ $\mathrm{O}_{3}+M$ and destroyed in Eq. (7), which is in photochemical balance (Brassuer et al., 2005). Considering this and the other photochemical equations presented by Makhlouf et al. (1995), the volumetric emission rate for the $\mathrm{OH}(6-2)$ band can be expressed as

$$
\begin{aligned}
& V_{\mathrm{OH}(6-2)}= \\
& \frac{+\sum_{v=7}^{9} A(v, 6)[\mathrm{OH}(v)]+\sum_{v=7}^{9}[\mathrm{OH}(v)]\left\{\sum_{M_{i}} k_{2}^{Q_{i}}(v, 6)\left[M_{i}\right]\right\}}{\sum_{M_{i}} k_{L}^{M_{i}}(6)\left[M_{i}\right]+A(6),}
\end{aligned}
$$

where $k_{1}$ is the reaction coefficient for Eq. (7); $f(6)$ is the quantum yield for the vibrational level $6 ; A(6,2), A(v, 6)$, and $A(6)$ are the Einstein transition probabilities; $k_{2}^{Q_{i}}$ and $k_{L}^{M_{i}}$ are the collisional cascade production and quenching coefficients, respectively, between the $\mathrm{OH}$ excited states and other species (primarily $\mathrm{O}_{2}$ and $\mathrm{N}_{2}$ ).

To calculate the $\mathrm{OH}(6-2)$ band from Eq. (8), we have used the reaction coefficients and other parameters from Makhlouf et al. (1995), except the Einstein transitions probabilities, which we obtained from Langhoff et al. (1986).

\subsection{Airglow simulations}

The steady-state photochemistry approach was used in previous studies that involved the interaction between atmospheric waves and the airglow (Vargas et al., 2007; Liu and Swenson, 2003; Ward, 1999). In the present study, the dynamical processes associated with the waves are introduced through perturbations in the constituents and temperature. As noted by Snively et al. (2010), the chemical response is faster than the wave perturbations and it is valid when the wave periods are much longer than the timescales of the chemical reactions. According to Makhlouf et al. (1998), the hypothesis of photochemical equilibrium holds for the atomic and molecular oxygen. For the OH emissions, Liu and Swenson (2003) noted that such hypothesis was valid for waves with periods longer than $20 \mathrm{~min}$. Because planetary-wave processes have temporal scales of days, the steady-state photochemistry approach to calculate the airglow emission rates from the Kyushu GCM is acceptable. 


\section{Results and discussion}

\subsection{Planetary-wave signatures}

Temporal variations in the $\mathrm{OI} 5577, \mathrm{O}_{2} b(0-1)$, and $\mathrm{OH}(6-$ 2) emission rates were simulated as described in Sect. 2.1. Planetary-wave-induced variations in the MLT airglow emissions have been reported from middle-latitude ground-based observations (e.g., Takahashi et al., 2013; Lopez-Gonzalez et al., 2009). To study the effect of the planetary-wave activity on the airglow and to compare it with the ground-based MLT airglow measurements, we initially analyzed the variability in the emissions at $43^{\circ} \mathrm{N}$ and $143^{\circ} \mathrm{E}$, which is the nearest model grid point to the Rikubetsu airglow observatory at $\left(43.5^{\circ} \mathrm{N}, 143.8^{\circ} \mathrm{E}\right)$. Dominant periodic oscillations were identified in the averaged airglow integrated intensities. Figure 1 shows the wavelet spectrum of the simulated $\mathrm{O}_{2} b(0-1)$ emission with the assimilated data in 2005. To calculate the power spectrum, the Morlet wavelet transform was used (Torrence and Compo, 1998). Periodic oscillations near 5, 10, and 16 days appear intermittently throughout the year. The wave activity is more intense during the autumn and winter months. From the spring equinox to the autumn equinox, the wave activity decreases. In the present case, there is some activity related to the 2-day wave after the summer solstice. Longer-period oscillations, i.e., 10- and 16-day oscillations, have significant spectral energy before and after the spring and autumn equinoxes, respectively. The spectrum shows three well-defined periodic oscillations at the periods near 5, 10, and 16 days. The 10-day oscillation appears on approximately day 90 (March/April). Between days 300 and 330 (November), there is an oscillation whose spectral energy spreads from 10 to 16 days and is centered at 12 days. Immediately after day 330, there is also a well-defined 6.5day oscillation. The spectral contents of the OI5577 and $\mathrm{OH}(6-2)$ emissions (not shown here) show essentially identical features to those in Fig. 1 for the $\mathrm{O}_{2} b(0-1)$ emission. The amplitudes of variation in these emissions appear independent from the period of oscillation (6.5-16 days). However, these three emissions show different amplitudes of variation against the passage of waves. Relative to the mean intensity, the amplitudes are 7-8\% in the $\mathrm{OH}(6-2)$ emission, 13$17 \%$ in the $O_{2} b(0-1)$ emission, and $22-34 \%$ in the OI5577 emission. Table 1 shows the relative amplitudes induced by the 6.5-, 10-, and 16-day planetary-scale waves in the emissions. The relative amplitudes of the waves for different periods systematically increase from the $\mathrm{OH}(6-2)$ to $\mathrm{O}_{2} b(0-1)$ and to OI557.7 nm emissions. Ground-based observations of planetary-wave signatures in the airglow also depict a similar scenario (e.g., Lopez-Gonzales et al., 2009; Takahashi et al., 2013). Such behavior may be related to the dependence of each emission on the atomic oxygen concentration, which is approximately linear, squared, and cubic in the $\mathrm{OH}(6-2)$, $\mathrm{O}_{2} b(0-1)$, and OI557.7 $\mathrm{nm}$ emissions, respectively, as shown in Eqs. (5), (6), and (8).
Table 1. Relative amplitudes induced by the 6.5-, 10-, and 16-day waves in the $\mathrm{OH}(6-2), \mathrm{O}_{2} b(0-1)$, and OI5577 emissions.

\begin{tabular}{lrrr}
\hline & $\mathrm{OH}(6-2)$ & $\mathrm{O}_{2} b(0-1)$ & $\mathrm{OI} 5577$ \\
\hline 6.5-day wave & $8 \%$ & $17 \%$ & $34 \%$ \\
10-day wave & $8 \%$ & $17 \%$ & $24 \%$ \\
16-day wave & $7 \%$ & $13 \%$ & $22 \%$ \\
\hline
\end{tabular}

The planetary-wave activity in the MLT region varies as a function of time and space, which reflects the variability in the sources and conditions of propagation. Signatures of such periodic oscillations are clearly observed in the wind structures. For the middle latitudes, waves with longer periods of 10 and 16 days are common features in autumn and winter seasons, 5-day waves frequently appear around equinoxes, and 2-day waves intensify in the summer (Chshyolkova et al., 2005; Jiang et al., 2005, 2008). For the airglow and planetary-wave observations, López-Gonzalez et al. (2009) extensively investigated the planetary-wave activity in the middle-latitude MLT based on ground measurements of the airglow at the Sierra Nevada observatory $\left(37.06^{\circ} \mathrm{N}, 3.38^{\circ} \mathrm{W}\right)$. Their analysis, which covered almost 10 years (1998-2007), showed 10- and 16-day oscillations that peaked in autumn and winter and 5-day oscillations with maximum intensifications near the equinoxes and strong quasi-2-day oscillations in winter and summer. By analyzing the airglow and wind data at Rikubetsu $\left(43.5^{\circ} \mathrm{N}, 143.8^{\circ} \mathrm{E}\right)$ and Wakkanai $\left(45.4^{\circ} \mathrm{N}, 141.7^{\circ} \mathrm{E}\right)$, respectively, Takahashi et al. (2013) showed a similar scenario. Large amplitudes of oscillation of the airglow intensities were reported in these two studies. For 10- and 16-day waves, Takahashi et al. (2013) reported amplitudes of up to $57 \%$ in the OI5577, $51 \%$ in the $\mathrm{O}_{2} b(0-1)$, and $29 \%$ in the $\mathrm{OH}(6-2)$. The amplitudes of oscillation reported by López-Gonzalez et al. (2009) also presented higher amplitudes of oscillation than our values here. Despite the difference in the magnitudes, the amplitudes presented here show identical behavior in each emission, i.e., the amplitudes in the OI5577 and $\mathrm{O}_{2}(0-1)$ are systematically higher than that in $\mathrm{OH}(6-2)$. Therefore, the planetarywave signatures in the MLT airglow simulated by the Kyushu GCM essentially exhibit a similar seasonal variation to those in airglow and wind measurements. This finding indicates that the Kyushu GCM reproduces well the planetary-wave activity in the airglow and some of its features in the MLT.

\subsection{The 10-day wave}

The ground-based measurements of the MLT airglow at Rikubetsu observatory, which Takahashi et al. (2013) reported, showed the presence of quasi-10-day oscillations during days 10-100 in 2005. There has only been little investigation of the 10-day wave in the MLT. Thus, we focused attention on this periodic oscillation. Figure 2 shows the nightly averaged volume emission rates (VERs) during days 75-110 

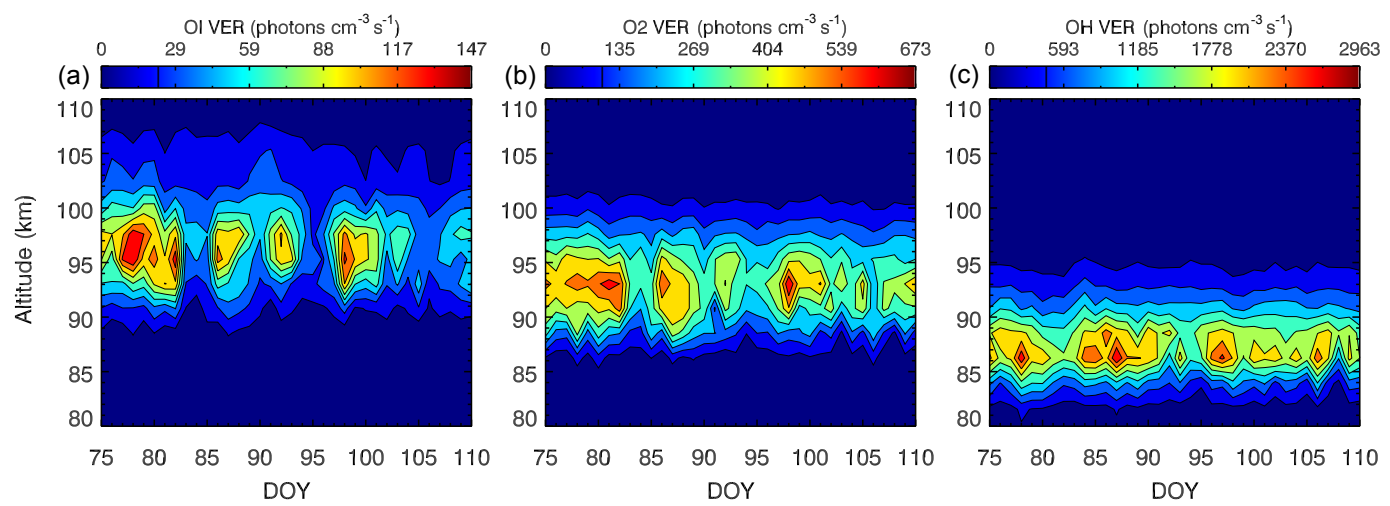

Figure 1. Time-altitude distribution of the volumetric emission rates of the $\mathrm{OI} 5577(\mathbf{a}), \mathrm{O}_{2} b(0-1)(\mathbf{b})$, and $\mathrm{OH}(6-2)(\mathbf{c})$ at $43^{\circ} \mathrm{N}$ and $143^{\circ} \mathrm{E}$. Time interval covers March and April for 2005 simulations.

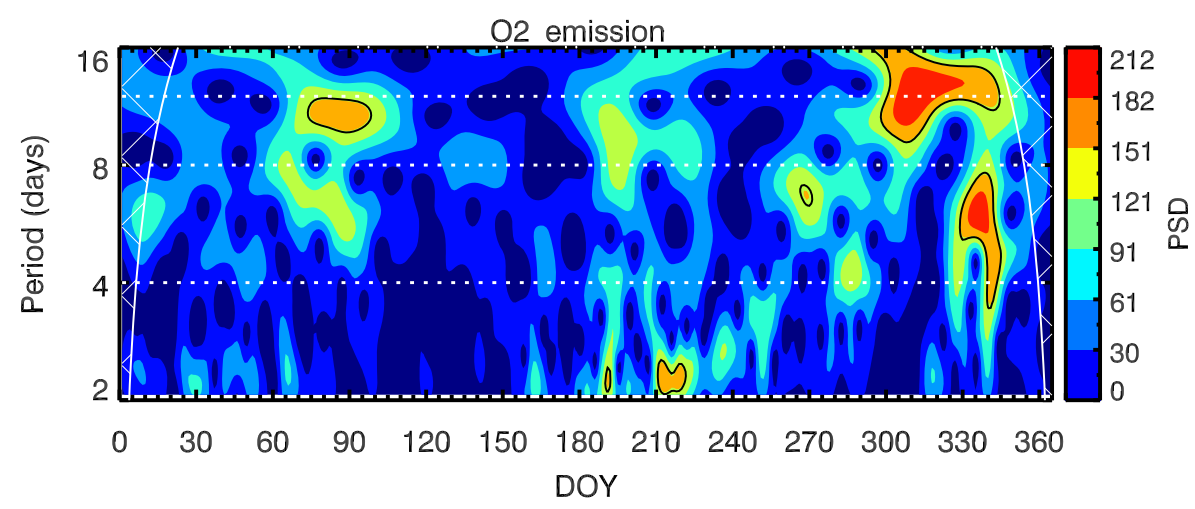

Figure 2. Wavelet spectrum of the nightly mean column intensity of the $\mathrm{O}_{2} b(0-1)$ emission rates simulated by the Kyushu GCM at $43^{\circ} \mathrm{N}$ and $143^{\circ} \mathrm{E}$ from January to December 2005.

of the OI5577, $\mathrm{O}_{2} b(0-1)$, and $\mathrm{OH}(6-2)$ emissions at $43^{\circ} \mathrm{N}$ and $143^{\circ} \mathrm{E}$, which is the closest grid point to the Rikubetsu airglow observatory. All of the three emissions exhibit a clear variation of approximately 10 days that lasted approximately two cycles, and the first maximum was between days 75 and 80. The 10-day oscillation exhibits relatively distinct magnitudes in each emission. In the OI5577 emission, the VER is drastically reduced during the minimum phase. The reduction is gradually lower in the $\mathrm{O}_{2}(0-1)$ and $\mathrm{OH}(6-2)$ emission rates. From the harmonic analysis, we estimated the amplitudes of the 10-day oscillation relative to the mean value during the studied period. To compare with ground-based observations, we integrated the emission rates to obtain the nightly averaged intensities. The integrated intensities are expressed in Rayleigh (R). The amplitude perturbations are $24 \%$ in the OI5577, $17 \%$ in the $\mathrm{O}_{2} b(0-1)$, and $8 \%$ in the $\mathrm{OH}(6-2)$.

The 10-day oscillations are primarily associated with the 10-day Rossby normal mode. To investigate the zonal structure of this oscillation, we applied the space-time spectral analysis (Hayashi, 1971), which simultaneously reveals the zonal wavenumber and the frequency (period) in the data. Figure 3 shows space-time spectra for the simulated OI5577,
$\mathrm{O}_{2} b(0-1)$, and $\mathrm{OH}(6-2)$ integrated intensities at $43^{\circ} \mathrm{N}$. The data correspond to the interval of days 75-110. A spectral peak that corresponds to the zonal wavenumber -1 and a period of approximately 10 days are clearly observed in all three emissions. The negative (positive) zonal wavenumber corresponds to the westward (eastward) propagation. Therefore, the 10-day oscillation in the airglow exhibits characteristics of a westward-propagating wave with zonal wavenumber 1 . In addition to this wave, there is also a secondary peak related to a 6.5-day westward-propagating wave with a zonal wavenumber of 1 . Interestingly, the 6.5 -day wave amplitude is particularly strong in the $\mathrm{OH}(6-2)$ emission. Its amplitude is similar to that of the 10-day wave. The signature of the 6.5-day wave is observed in the emission rates in Fig. 2 on approximately day 90 , when there is a split during the maximum phase of the 10-day wave. The superposition of the 10-day and 6.5-day waves is more pronounced in the $\mathrm{OH}(6-$ 2 ) emission, which may suggest a vertical damping of the 6.5-day wave.

To characterize the latitudinal structure of the 10-day wave field, we again applied the space-time spectral analysis to the emissions. The latitudinal structures of the wave ampli- 

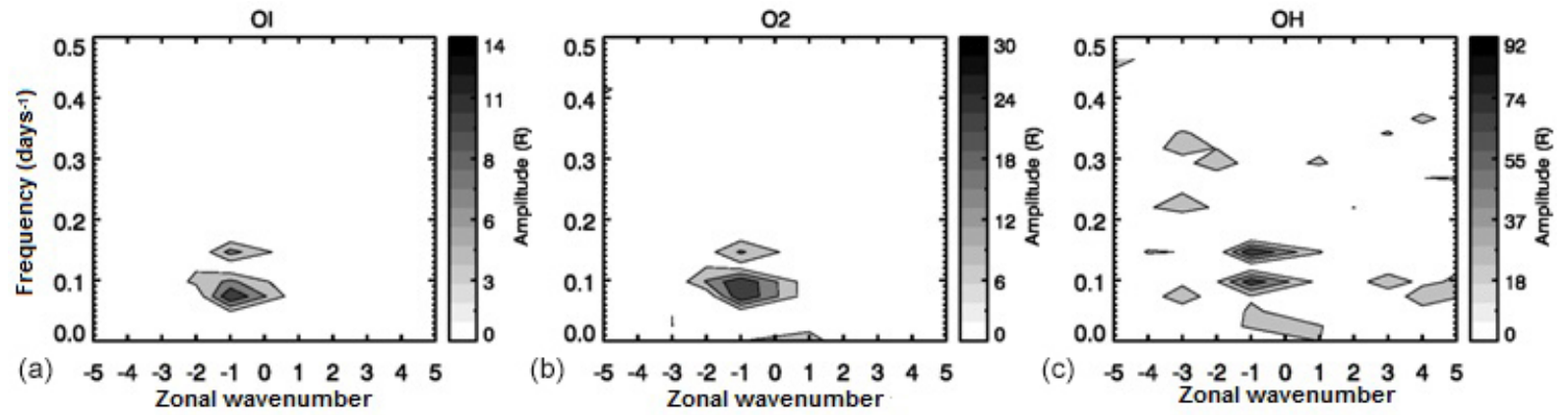

Figure 3. Space-time spectra of the $\mathrm{OI} 5577$ (a), $\mathrm{O}_{2} b(0-1)(\mathbf{b})$, and $\mathrm{OH}(6-2)(\mathbf{c})$ emissions at $43^{\circ} \mathrm{N}$.
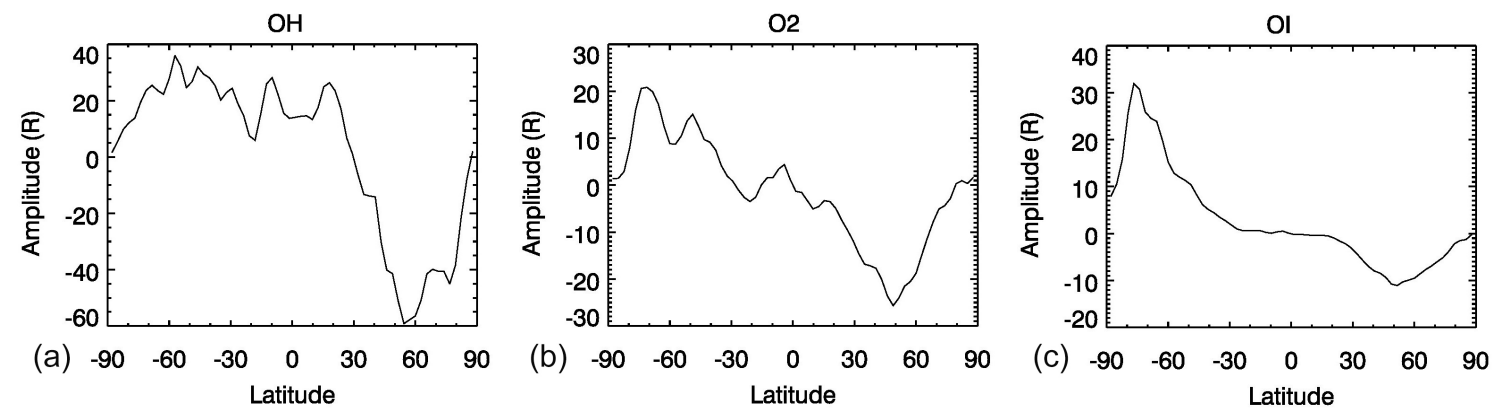

Figure 4. Latitudinal structure of the zonal wavenumber 1, westward-propagating 10-day wave.

tude are shown in Fig. 4. The data corresponds to the interval of days 75-110 around the March equinox. In general, the amplitude of the 10-day wave peaks at middle latitudes and minimizes at the equator and poles. The wave also exhibits an asymmetric amplitude distribution around the equator. Comparing the amplitudes between the Northern and Southern Hemispheres, we notice that those in the $\mathrm{OH}(6-2)$ and $\mathrm{O}_{2} b(0-1)$ emissions are higher in the Northern Hemisphere, whereas the amplitudes of OI5577 are higher in the Southern Hemisphere. On the other hand, the amplitudes of the OI5577 emission are higher in the Southern Hemisphere. In addition, the wave amplitude structure of the $\mathrm{OH}$ emission is slightly distorted, and its zero level is displaced by approximately $30^{\circ}$ from the equator. The 10-day wave, which is normally associated with the free Rossby normal mode (1, -3 ), is the first asymmetric mode from classical planetarywave theory (Forbes, 1995). Its horizontal structure in density, temperature, and vertical and zonal wind is antisymmetric with respect to the equatorial node and peaks at middle latitudes. The characteristics of the horizontal structure of the presented 10-day wave here are similar to the aforementioned characteristics, which indicates that the airglow variations in March/April are consistent with a signature of the normal mode $(1,-3)$. The 10 -day oscillation identified in this work was observed in the airglow and wind measurements by Takahashi et al. (2013), which reinforces the model's capability to reproduce the planetary-wave activity in the MLT airglow.

\subsection{Airglow response to planetary waves}

The comparison of the day-to-day variations in the MLT airglow intensities between the observation and the model simulation shows that the Kyushu GCM can reproduce the planetary-wave activity in the MLT airglow well. Furthermore, it is well known that the vertical transport process, particularly that of atomic oxygen, has an important role in the airglow intensity variability (e.g., Cho and Shepherd, 2006). Thus, a diagnostic post-processing analysis was performed to evaluate the importance of the vertical transport of atomic oxygen via eddy diffusion and advection due to the wave wind field. The vertical transport of atomic oxygen via advection and eddy diffusion was calculated as follows:

$f_{\mathrm{adv}}=w[\mathrm{O}]$,

$f_{\text {eddy }}=-K\left[\mathrm{~N}_{2}\right] \frac{\mathrm{d}}{\mathrm{d} z}\left(\frac{[\mathrm{O}]}{\left[\mathrm{N}_{2}\right]}\right)$,

where $w$ is the vertical velocity, $[\mathrm{O}]$ and $\left[\mathrm{N}_{2}\right]$ are, respectively, the atomic oxygen and molecular nitrogen concentrations, $z$ is the vertical coordinate, and $\mathrm{K}$ is the eddy diffusion coefficient, which was obtained from Chen (2012).

We investigated the vertical transport of atomic oxygen during intervals when planetary-wave signatures in the airglow were observed. Figure 5 shows the daily mean vertical transport of atomic oxygen (in $\mathrm{cm}^{-2} \mathrm{~s}^{-1}$ ) due to advection (a) and eddy diffusion (b) during days 75-110 (March/April) and 300-330 (October/November). The gray and blank areas 

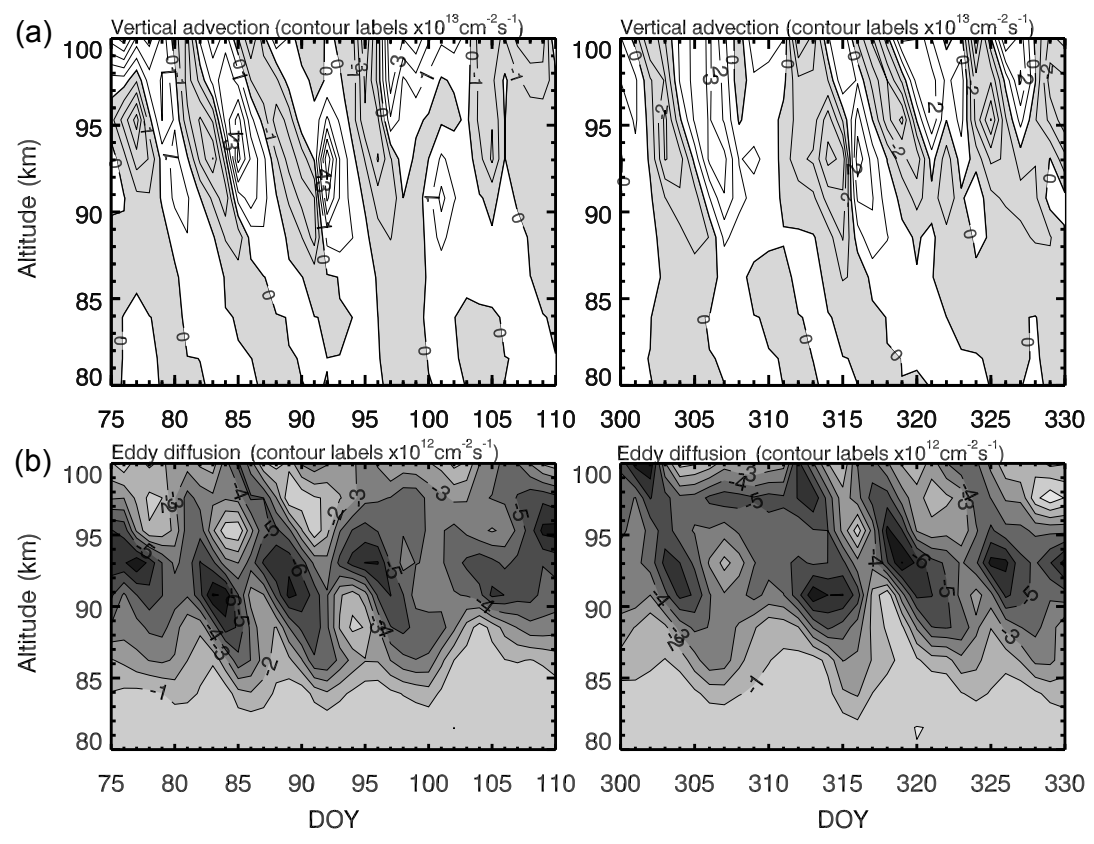

Figure 5. Daily mean transport of atomic oxygen by vertical advection (a) and eddy diffusion (b) at $43^{\circ} \mathrm{N}$ and $143^{\circ}$ E. Contour labels $\times 10^{13} \mathrm{~cm}^{-2} \mathrm{~s}^{-1}$ for vertical advection and $\times 10^{12} \mathrm{~cm}^{-2} \mathrm{~s}^{-1}$ for eddy diffusion.
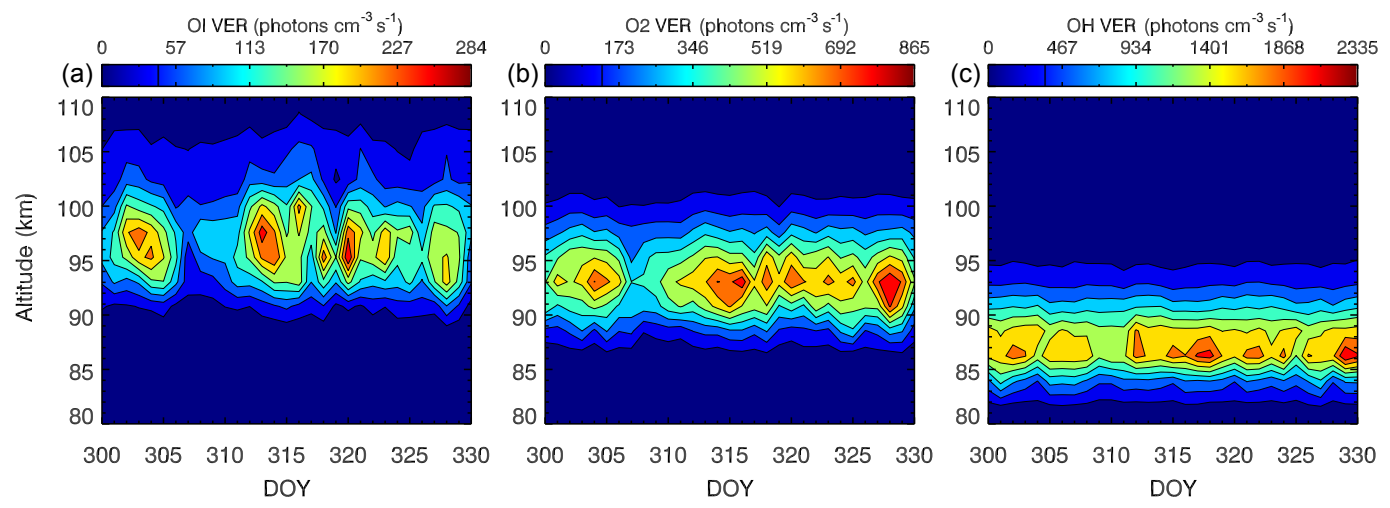

Figure 6. Time-altitude distribution of the volumetric emission rates of the $\mathrm{OI} 5577(\mathbf{a}), \mathrm{O}_{2} b(0-1)(\mathbf{b})$, and $\mathrm{OH}(6-2)(\mathbf{c})$ at $43^{\circ} \mathrm{N}$ and $143^{\circ} \mathrm{E}$. Time interval covers October and November for 2005 simulations.

indicate the downward and upward transports, respectively. During both intervals, the vertical transport of atomic oxygen by advection and eddy diffusion exhibits periodic variations, which are associated with the 10-day wave like those observed in the airglow. This feature indicates a direct relationship between the vertical transport of atomic oxygen due to the 10-day wave and the correspondent airglow-induced variability. Despite similar time variabilities, the advection and eddy diffusion present distinct characteristics. The advection changes direction (alternating between upward and downward flux), whereas the eddy diffusion is predominantly downward. Furthermore, the magnitudes of eddy diffusion are approximately 10 times lower than the magnitude of vertical advection.
To understand the relationship between the vertical transport of atomic oxygen and the airglow periodic oscillations, we compared their temporal variation. Figure 2 shows that emission rates are maximal on approximately days 80,90 , and 100 and minimal on approximately days 85 and 95 . Comparing the temporal variability in the emissions rates shown in Fig. 2 with the vertical transport processes shown in Fig. 5, we note that for most of the altitudes, the high emission rates match the downward flux due to vertical advection and intensifications in the downward eddy diffusion. Meanwhile, the low emission rates are related to the upward flux due to vertical advection and decreasing eddy diffusion. Figure 6 shows the volume emission rates of $\mathrm{OH}(6-2), \mathrm{O}_{2} b(0-$ 1 ), and OI5577 emissions during days 300-330, which cor- 
respond to the interval when 5- and 16-day oscillations were observed. This figure shows that the variability in the airglow emission rates and vertical transport of atomic oxygen is similar to that for the 10-day wave; i.e., high emission rates are related to the downward advection and increasing downward eddy diffusion and vice versa. The vertical wind generated by wave propagations primarily drives the vertical advection. Therefore, the vertical motion induced by the wave wind field is the primary source of the observed periodic 5-, 10-, and 16-day variations observed in the airglow emissions. As noted by Liu et al. (2008), the eddy diffusion contributes to the background intensities by transporting atomic oxygen downward, and the vertical advection explains the time variability in the emissions due to wave-induced vertical motion.

The airglow variability as a result of vertical motions has been attributed to quasi-adiabatic processes that conserve the atomic oxygen mixing ratio (Ward at al., 1994, 1997). In this case, when the atomic oxygen mixing ratio increases with altitude in the MLT, the downward motion brings down the atomic-oxygen-rich air, and then emission rates increase. In contrast, in the upward motion, the proportionally atomicoxygen-poor air is moved up, and then emission rates decrease. The additional effect of this quasi-adiabatic process is to increase and decrease the temperature of the air during the downward and upward displacements, respectively. Although, the airglow variability is the result of many physical and chemical processes that occur together, the evidence presented here indicates that the airglow response to the penetration of planetary waves in the emission layers is primarily driven by the vertical transport of atomic oxygen. Ward et al. (1997) explained the enhancement of airglow emission rates with the vertical advection induced by 2 -day planetary waves instead of the atomic-oxygen mixing ratio caused by the wave-breaking process. Our simulation model results also indicate that the longer-period planetary waves (5-, 10-, 16-day) may produce vertical advection and result in the airglow day-to-day variability.

\section{Conclusions}

In this study, we investigated the effects of planetary waves on the MLT airglow by simulating the $\mathrm{OH}(6-2), \mathrm{O}_{2} b(0-$ 1), and OI5577 MLT emissions using the general circulation model of Kyushu University. Periodic variations of 220 days in the simulated emissions were observed over the course of the year. At middle latitudes, the wave activity intensifies from autumn to spring equinoxes, where the 5-, 10-, and 16-day waves dominate the airglow variability. The planetary-wave activity in the simulated airglow exhibits a similar seasonal variability to that observed in the wind and airglow, which indicates that the model can reproduce the airglow variability induced by the planetary waves. The amplitudes of variation induced by the 5-, 10-, and 16-day planetary waves are $7-8 \%$ in the $\mathrm{OH}(6-2)$ emission, $13-17 \%$ in the $\mathrm{O}_{2} b(0-1)$ emission, and $22-34 \%$ in the OI5577 emission. It is revealed that the vertical transport of atomic oxygen by vertical advection and eddy diffusion generated by the 5-, 10-, and 16-day planetary waves is responsible for the observed day-to-day variabilities of the MLT airglow.

Data availability. The model data used in this study are available upon request to the authors.

Competing interests. The authors declare that they have no conflict of interest.

Acknowledgements. We thank the Conselho Nacional de Desenvolvimento Científico e Tecnológico-CNPq (processes no. 141813/2009-1, 200228/2011-0, and 305461/2015-0) for the financial support for the present study. The authors also thank Kazuo Shiokawa at the Institute of Space-Earth Environmental Research (ISEE), Nagoya University, who provided the airglow data from Rikubetsu, Japan.

The topical editor, Keisuke Hosokawa, thanks two anonymous referees for help in evaluating this paper.

\section{References}

Angelatis i Coll, M. and Forbes, J. M.: Dynamical influences on atomic oxygen and $5577 \AA$ emission rates in the lower thermosphere, Geophys. Res. Lett., 25, 461-464, 1998.

Barth, C. A.: The 5577-angstrom airglow, Science, 134, 1426-1430, 1961.

Brasseur, G. P. and Solomon, S.: Aeronomy of the Middle Atmosphere, 3th Edn., Springer, Dordrecht, 2005.

Buriti, R. A., Takahashi, H., Lima, L. M., and Medeiros, A. F. Equatorial planetary waves in the mesosphere observed by airglow periodic oscillations, Adv. Space Res., 35, 2031-2036, 2005.

Chen, Y. W.: Analyses of fast and ultrafast kelvin waves simulated by the Kyushu-GCM: wave behavior and excitation sources, $\mathrm{PhD}$ Thesis - Kyushu University, Fukuoka-Japan, 119 pp., 2012.

Cho, Y. M. and Shepherd, G. G.: Correlation of airglow temperature and emission rate at Resolute Bay $\left(74.68^{\circ} \mathrm{N}\right)$, over four winters (2001-2005), Geophys. Res. Lett., 33, L06815, https://doi.org/10.1029/2005GL025298, 2006.

Chshyolkova, T., Manson, A. H., and Meek, C. E.: Climatology of the quasi two-day wave over Saskatoon $\left(52^{\circ} \mathrm{N}, 107^{\circ} \mathrm{W}\right): 14$ Years of MF radar observations, Adv. Space Res., 35, 20112016, 2005.

Espy, P. J. and Witt, G.: Observation of a quasi 16-day oscillation in the polar summer mesospheric temperature, Geophys. Res. Lett., 23, 1071-1074, 1996.

Espy, P. J., Stegman, J., and Witt, G.: Interannual variations of the quasi-16-day oscillation in the polar summer mesospheric temperature, J. Geophys. Res.-Atmos., 102, 1983-1990, 1997.

Forbes, J. M.: Tidal and planetary waves, in: The Upper Mesosphere and Lower Thermosphere: A Review of Experiment and Theory, Geoph. Monog. Series, 87, 67-87, 1995. 
Fukuyama, K.: Airglow variations and dynamics in the lower thermosphere and upper mesosphere - I. Diurnal variation and its seasonal dependency, J. Atmos. Terr. Phys., 38, 1279-1287, 1976.

Hayashi, Y.: A generalized method of resolving disturbances into progressive and retrogressive waves by space Fourier and time cross-spectral analyses, J. Meteorol. Soc. Jpn., 49, 125-128, 1971.

Horinouchi, T.: Simulated breaking of convectively generated mesoscale gravity waves and airglow modulation, J. Atmos. Terr. Phys., 66, 755-767, 2004.

Jiang, G., Xiong, J., Wan, W., Ning, B., Liu, L., Vincent, R. A., and Reid, I.: The 16-day waves in the mesosphere and lower thermosphere over Wuhan $\left(30.6^{\circ} \mathrm{N}, 114.5^{\circ} \mathrm{E}\right)$ and Adelaide $\left(35^{\circ} \mathrm{S}\right.$, $138^{\circ}$ E), Adv. Space Res., 35, 2005-2010, 2005.

Jiang, G., Xiong, J., Wan, W., Ning, B., and Liu, L.: Observation of 6.5-day waves in the MLT region over Wuhan, J. Atmos. Sol.Terr. Phys., 70, 41-48, 2008.

Krassovsky, V. I.: Infrasonic variations of $\mathrm{OH}$ emission in the upper atmosphere, Ann. Geophys., 28, 739-746, 1972.

Langhoff, S. R., Werner, H. J., and Rosmus, P.: Theoretical Transition-Probabilities for the Oh Meinel System, J. Mol. Spectrosc., 118, 507-529, 1986.

Lichstein, G. S., Forbes, J. M., Coll, M. A. I., Takahashi, H., Gobbi, D., and Buriti, R. A.: Quasi-3-day kelvin wave and the OI(5577 angstrom), $\mathrm{OH}(6,2)$ Meinel, and O-2(0,1) emissions, Geophys. Res. Lett., 29, 1043-1046, 2002.

Liu, A. Z. and Swenson, G. R.: A modeling study of O2 and $\mathrm{OH}$ airglow perturbations induced by atmospheric gravity waves, J. Geophys. Res.-Atmos., 108, D44151, https://doi.org/10.1029/2002JD002474, 2003.

Liu, G. and Shepherd, G. G.: An empirical model for the altitude of the OH nightglow emission, Geophys. Res. Lett., 33, L09805, https://doi.org/10.1029/2005GL025297, 2006.

Liu, G. P., Shepherd, G. G., and Roble, R. G.: Seasonal variations of the nighttime $\mathrm{O}(1 \mathrm{~S})$ and $\mathrm{OH}$ airglow emission rates at mid-to-high latitudes in the context of the large-scale circulation, J. Geophys. Res.-Space, 113, A06302, https://doi.org/10.1029/2007JA012854, 2008.

López-González, M. J., Rodríguez, E., García-Comas, M., Costa, V., Shepherd, M. G., Shepherd, G. G., Aushev, V. M., and Sargoytchev, S.: Climatology of planetary wave type oscillations with periods of 2-20 days derived from $\mathrm{O}_{2}$ atmospheric and $\mathrm{OH}(6-2)$ airglow observations at mid-latitude with SATI, Ann. Geophys., 27, 3645-3662, https://doi.org/10.5194/angeo27-3645-2009, 2009.

Makhlouf, U. B., Picard, R. H., and Winick, J. R.: PhotochemicalDynamical Modeling of the Measured Response of Airglow to Gravity-Waves, 1. Basic Model for Oh Airglow, J. Geophys. Res.-Atmos., 100, 11289-11311, 1995.

Makhlouf, U. B., Picard, R. H., Winick, J. R., and Tuan, T. F.: A model for the response of the atomic oxygen $557.7 \mathrm{~nm}$ and the $\mathrm{OH}$ Meinel airglow to atmospheric gravity waves in a realistic atmosphere, J. Geophys. Res.-Atmos., 103, 6261-6269, 1998.

McDade, I. C. and Llewellyn, E. J.: The excitation of $\mathrm{O}(1 \mathrm{~S})$ and $\mathrm{O}-2$ bands in the nightglow - a brief review and preview, Can. J. Phys., 64, 1626-1630, 1986.
Miyahara, S., Yoshida, Y., and Miyoshi, Y.: Dynamic coupling between the lower and upper-atmosphere by tides and gravitywaves, J. Atmos. Terr. Phys., 55, 1039-1053, 1993.

Miyoshi, Y.: Numerical simulation of the 5-day and 16-day waves in the mesopause region, Earth Planets Space, 51, 763-772, 1999.

Miyoshi, Y. and Fujiwara, H.: Day-to-day variations of migrating diurnal tide simulated by a GCM from the ground surface to the exobase, Geophys. Res. Lett., 30, 1789, https://doi.org/10.1029/2003GL017695, 2003.

Miyoshi, Y. and Fujiwara, H.: Excitation mechanism of intraseasonal oscillation in the equatorial mesosphere and lower thermosphere, J. Geophys. Res.-Atmos., 111, D14108, https://doi.org/10.1029/2005JD006993, 2006.

Onogi, K., Koide, H., Sakamoto, M., Kobayashi, S., Tsutsui, J., Hatsushika, H., Matsumoto, T., Yamazaki, N., Kamahori, H., Takahashi, K., Kato, K., Oyama, R., Ose, T., Kadokura, S., and Wada, K.: JRA-25: Japanese 25-year re-analysis project - progress and status, Q. J. Roy. Meteor. Soc., 131, 3259-268, 2005.

Shepherd, G. G., Thuillier, G., Solheim, B. H., Chandra, S., Cogger, L. L., Duboin, M. L., Evans, W. F. J., Gattinger, R. L., Gault, W. A., Herse, M., Hauchecorne, A., Lathuilliere, C., Llewellyn, E. J., Lowe, R. P., Teitelbaum, H., and Vial, F.: Longitudinal structure in atomic oxygen concentrations observed with WINDII on UARS, Geophys. Res. Lett., 20, 1303-1306, 1993.

Shepherd, G. G., Cho, Y. M., Liu, G. P., Shepherd, M. G., and Roble, R. G.: Airglow variability in the context of the global mesospheric circulation, J. Atmos. Sol.-Terr. Phys., 68, 2000-2011, 2006.

Sivjee, G. G., Walterscheid, R. L., and Mcewen, D. J. Planetary wave disturbances in the arctic winter mesopause over eureka $\left(80^{\circ} \mathrm{N}\right)$, Planet. Space Sci., 42, 973-986, 1994.

Snively, J. B., Pasko, V. P., and Taylor, M. J.: OH and OI airglow layer modulation by ducted short-period gravity waves: Effects of trapping altitude, J. Geophys. Res.-Space, 115, A11311, https://doi.org/10.1029/2009JA015236, 2010.

Takahashi, H., Buriti, R. A., Gobbi, D., and Batista, P. P.: Equatorial planetary wave signatures observed in mesospheric airglow emissions, J. Atmos. Sol.-Terr. Phys., 64, 1263-1272, 2002.

Takahashi, H., Shiokawa, K., Egito, F., Murayama, Y., Kawamura, S., and Wrasse, C. M.: Planetary wave induced wind and airglow oscillations in the middle latitude MLT region, J. Atmos. Sol.Terr. Phys., 98, 97-104, 2013.

Teitelbaum, H., Massebeuf, M., Fellous, J. L., Petitdidier, M., Christophe, J., and Blanco, F.: Simultaneous Measurements of Meteor Winds and Green Line Intensity Variations - GravityWaves and Planetary-Waves, J. Geophys. Res.-Space, 86, 7767 7770, 1981.

Torrence, C. and Compo, G. P.: A practical guide to wavelet analysis, B. Am. Meteorol. Soc., 79, 61-78, 1998.

Vargas, F., Swenson, G., Liu, A., and Gobbi, D.: O(S-1), OH, and O-2(b) airglow layer perturbations due to AGWs and their implied effects on the atmosphere, J. Geophys. Res.-Atmos., 112, D14102, https://doi.org/10.1029/2006JD007642, 2007.

Walterscheid, R. L. and Schubert, G.: Dynamical-chemical model of fluctuations in the $\mathrm{OH}$ airglow driven by migrating tides, stationary tides, and planetary-waves, J. Geophys. Res.-Space, 100, 17443-17449, 1995.

Ward, W. E., Rochon, Y. J., Mclandress, C., Wang, D. Y., Criswick, J. R., Solheim, B. H., and Shepherd, G. G.: Correlations between 
the mesospheric $\mathrm{o}(s-1)$ emission peak intensity and height, and temperature at $98 \mathrm{~km}$ using WINDII data, Adv. Space Res., 14, 57-60, 1994.

Ward, W. E., Solheim, B. H., and Shepherd, G. G.: Two day wave induced variations in the oxygen green line volume emission rate: WINDII observations, Geophys. Res. Lett., 24, 1127-1130, 1997.

Ward, W. E., Oberheide, J., Riese, M., Preusse, P., and Offermann, D.: Tidal signatures in temperature data from CRISTA 1 mission, J. Geophys. Res.-Atmos., 104, 16391-16403, 1999.

Wiens, R. H. and Weill, G.: Diurnal, annual and solar cycle variations of hydroxyl and sodium nightglow intensities in the Europe-Africa sector, Planet. Space Sci., 21, 1011-1027, 1973.
Xu, J., Smith, A. K., Jiang, G., Gao, H., Wei, Y., Mlynczak, M. G., and Russell III, J. M.: Strong longitudinal variations in the $\mathrm{OH}$ nightglow, Geophys. Res. Lett., 37, L21801, https://doi.org/10.1029/2010GL043972, 2010.

Yee, J. H., Crowley, G., Roble, R. G., Skinner, W. R., Burrage, M. D., and Hays, P. B.: Global simulations and observations of $\mathrm{O}(\mathrm{S}-1), \mathrm{O}-2(1 \Sigma)$ and $\mathrm{OH}$ mesospheric nightglow emissions, J. Geophys.Res.-Space, 102, 19949-19968, 1997. 